\title{
Validation of the Comic Strip Test to evaluate empathy in a Mexican population sample
}

\author{
Dania Nimbe Lima-Sánchez¹, Xóchitl Duque-Alarcón², Fiacro Jiménez-Ponce ${ }^{3 *}$, Rafael Salín-Pascual, \\ Francisco Morales-Carmona ${ }^{5}$ and Arturo Ongay Peréz ${ }^{6}$ \\ 'Department of Biomedical Informatics, Department of Psychiatry and Mental Health, Faculty of Medicine, Universidad Nacional Autónoma de \\ México (UNAM); ${ }^{2}$ Tlatelolco Neuropsychiatry Unit, Instituto de Seguridad y Servicios del Estado; ${ }^{3}$ Hospital General de México Eduardo Liceaga; \\ ${ }^{4}$ Department of Psychiatry and Mental Health, Faculty of Medicine, UNAM; ${ }^{5}$ Department of Psychology, Instituto Nacional de Perinatología Isidro \\ Espinosa de los Reyes; ${ }^{6}$ Family Intervention Clinic, Hospital Psiquiátrico Fray Bernardino Álvarez. City of Mexico, Mexico
}

\begin{abstract}
Introduction: Empathy is the ability of an individual to understand it from another cognitive and emotional point of view. Empathy is a complex that represents a retouch in its evaluation, so, it is necessary to have instruments validated in the Mexican population. Objective: Validation of the Comic Strip Test to evaluate empathy. Method: Sampling for convenience, based on internal consistency, convergent validity with the Empathy coefficient, construct validity in the factorial analysis, and the ability to discriminate between subjects with lack of empathy (psychopathology) and the control subjects through a curve ROC. Results: The comic strips test was evaluated in 86 controls, 19 patients with schizophrenia (Cronbach's alpha $=0.894$ ). The correlation with the empathy coefficient was 0.88 , with sensitivity of $81.3 \%$ and specificity of $38 \%$. Conclusions: The Comic Strip Test was validated with parametric psychometric parameters.
\end{abstract}

KEY WORDS: Empathy. Schizophrenia. Validation. Test. Mexico.

\section{Introduction}

The ability to communicate, understand the intentions and feelings of others is a vital tool for social activities. One of these skills is empathy, which is considered as the ability to understand and appropriately respond to the emotions, thoughts and behaviors of other people, putting oneself in someone else's place ${ }^{1}$. In most studies on empathy, components have been established that relate to areas of the social context, recognition of emotions and an adequate response to the environment ${ }^{2}$. Lack of empathy is associated with poor functioning, and is observed in patients with psychiatric disorders such as autism and schizophrenia ${ }^{3}$. In schizophrenia, the lack of empathy has been described as a common symptom of the disorder, and it can be identified in prodromal phases and be a factor to discriminate between patients and healthy subjects ${ }^{4-6}$; furthermore, the lack of empathy does not improve with standard pharmacological treatment, but it appears that oxytocin can be a candidate for treatment?

The assessment of empathy is complex due to the aforementioned components. Multiple tests have been proposed, which can be divided in two modalities: self-reports and response to the presentation of a paradigm. In the case of self-reports, one of the most commonly used tests is the empathy coefficient, designed by Baron-Cohen ${ }^{8}$. This test was designed based on the systematization theory, under a vision integrating three components: cognitive empathy, emotional reactivity and social tools. It shows adequate psychometric properties, with an internal consistency of $0.85^{9,10}$. In addition, research showing its
Gac Med Mex. 2019;155 (Suppl 1):S35-S38

Contents available at PubMed www.gacetamedicademexico.com 
usefulness in assessing the autistic spectrum, anorexia and in patients with schizophrenia has been reported, with its observations being correlated with genetic findings ${ }^{11}$. This scale considers 60 questions, out of which 28 are indicator items, while the rest are control items, with Likert-type answers that offer the following options: agree, partially agree, partially disagree and strongly disagree. It was planned to have clinical application. Validation of the test in the Mexican population was carried out in 200 subjects aged between 18 and 25 years and able to understand scales, with an internal consistency of 0.81 and a testretest reliability with an $r=0.80$ being obtained; mean score was 41.1 points $^{12}$.

On the other hand, in assessments based on the application of a paradigm, the usefulness of the comic strip test proposed by Vollm ${ }^{12}$ and subsequently modified by Lee ${ }^{13}$ has been demonstrated. This test takes into account the following elements: cognitive empathy, emotional empathy and inhibitory empathy, with physical causality as the control section. Each condition is rated with 12 comic strips illustrating different scenarios. The drawings used in this study were based on those originally developed by Völlm et al. ${ }^{12}$, and that were subsequently modified by Lee ${ }^{13}$. The latter author kindly provided us with the Comic Strip Test through a personal communication. Each comic strip consists of three panels that illustrate an interaction between two characters. The main character or protagonist, who is shown in color violet, has an empathetic response with the other character, responding to the intention or emotion of the latter. The four types of cartoons were validated by Lee in 2010, in a pilot study with 16 healthy subjects aged between 24 and 35 years; sensitivity and specificity were not reported in his results ${ }^{13}$.

Notwithstanding the aforementioned precedents, there is still no consensus on how to assess empathy, and the Comic Strip Test has not been validated or used in Mexico.

The purpose of this work is to find out the psychometric properties of the Comic Strip Test in a sample of Mexican subjects.

\section{Methods}

Sample selection was by convenience. The participants in this study were medical students from the National Autonomous University of Mexico, rehabilitation students and open population. The instrument was individually applied by the study researchers, in an area dedicated to this purpose (physician's office or classroom).

To examine the sensitivity to detect individuals expected to show an empathy deficit, patients with schizophrenia, who were formally diagnosed by psychiatrists, using the diagnostic criteria of the International Classification of Diseases (ICD), Version 10, at the Fray Bernardino Álvarez Psychiatric Hospital were assessed. Subsequently, the subjects of each group were rated and matched by age and gender against the control group.

To measure the validity of the construct, a Bartlett sphericity test was initially carried out. This test examines whether the data of each test behaved spherically and whether a factor analysis might be performed. Baron-Cohen empathy coefficient was used to assess for convergent validity.

Internal consistency was obtained by calculating Cronbach's $\alpha$. Test-retest reliability was assessed in 80 subjects. Finally, a ROC curve graph was plotted to measure sensitivity and specificity.

The study protocol was approved by the Research and Ethics Committees of the Fray Bernardino Álvarez Psychiatric Hospital. In all cases was the informed consent process carried out, with research subjects' identity being handled under confidentiality standards.

\section{Results}

A pilot test was initially carried out on ten healthy subjects to observe comprehension and applicability; subsequently the test was applied to 105 subjects, out of which 86 were medical students, rehabilitation technicians and patient companions (55 females and 31 males); 19 subjects were schizophrenic patients (10 women and 9 men) who were in remission phase as inpatients of the Fray Bernardino Álvarez Psychiatric Hospital (Table 1). A comparison was made between women and men with Student's t-test for independent samples, with no significant differences being found (t: $0.455 ; p=0.650$ ).

Internal consistency of the test was $\alpha=0.843$. Convergent validity was assessed with the empathy coefficient proposed by Baron-Cohen, by means of which a correlation $r=0.88(p=0.0001)$ was obtained; in addition, consistency of the scale was assessed two months after its application in a subsample of 80 subjects, with a correlation $r=0.572(p=0.03)$ being obtained. Bartlett's test for sphericity $(p=0.406)$ and 
Table 1. Sample demographic data divided by gender. The table indicates the sample distribution by age and gender, where a larger percentage of women is observed

\begin{tabular}{|l|c|c|}
\hline \multirow{2}{*}{ Variable } & \multicolumn{2}{|c|}{ Comic strips } \\
\cline { 2 - 3 } & $\begin{array}{c}\text { Controls } \\
n(\%)\end{array}$ & $\begin{array}{c}\text { Schizophrenics } \\
n(\%)\end{array}$ \\
\hline $\begin{array}{l}\text { Gender } \\
\text { Females } \\
\text { Males }\end{array}$ & 55 & 10 \\
\hline Age, years (SD) & 31 & 9 \\
\hline
\end{tabular}

SD: standard deviation.

Table 2. Comic Strip Test results comparison between patients with schizophrenia and control subjects. This table shows the comparison between controls and patients matched by age and gender in both tests, with differences in all Comic Strip test parameters being shown

\begin{tabular}{l|c|c|c|c|}
\hline Variable & Patients & Controls & t-test & Significance \\
\hline Comic Strips & & & & \\
\hline $\begin{array}{l}\text { Cognitive empathy } \\
\text { Emotional empathy }\end{array}$ & $8.8(2.4)$ & $10.7(1.2)$ & -2.89 & 0.006 \\
\hline $\begin{array}{l}\text { Inhibitory empathy } \\
\text { Physical causality }\end{array}$ & $9.8(2.1)$ & $10.38(1.6)$ & -6.08 & 0.0001 \\
\hline $\begin{array}{l}\text { Total Comic Strip } \\
\text { Test }\end{array}$ & $33.84(6.8)$ & -2.018 & 0.09 \\
\hline
\end{tabular}

the Kaiser-Mayer-Olkin sample adequacy test $\left(\chi^{2}: 2012.6 ; p=0.001\right)$ were carried out. The rotated component matrix of showed a tendency towards correlating factors 1 and 2, but the rest of factors showed an adequate differentiation between each other. With regard to the factor analysis, most items of the Comic Strip test showed a tendency to be found in factor one; there were two items, 42 and 46, that showed no correlation with any factor.

\section{ROC curves}

The Comic Strip test showed a cut-off point of 41.5 out of a total of 48 , with a sensitivity of 0.813 and specificity of 0.338 being obtained (area: 0.851 ; $\mathrm{p}=0.0001$ ) (Fig. 1).

Patients were matched with controls by age and gender groups, with all patients showing significantly poorer results in all sections of the test (Table 2).

\section{Discussion}

Empathy is a skill that is used in daily life, given that human beings are highly sociable and it is a

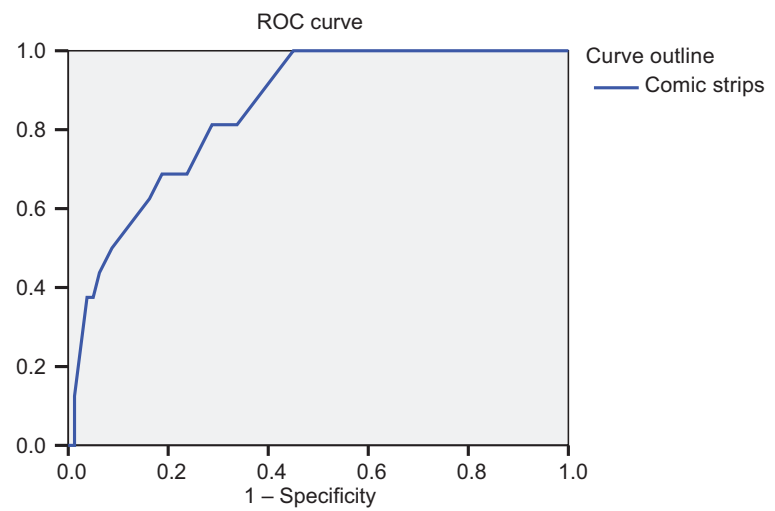

Figure 1. Comic Strip Test and empathy coefficient ROC curve. The $R O C$ curve is observed in this graph, with a significant curve value being obtained.

fundamental tool for interaction; but despite its importance there is still a lack of consensus on its definition due to the complexity involved ${ }^{14}$. This is reflected on the multiple anatomical areas of the brain that are activated during its functioning, and that have a highly important genetic component ${ }^{15}$. In addition, alterations can be found in different pathological states, as in the case of schizophrenia, where it causes global dysfunction and can be associated with metacognitive processes 4 .

In the Comic Strips Test validation results we can observe that, from the psychometric point of view, the values obtained in the study were similar to those referred to by Lee ${ }^{13}$, which makes it a useful tool with less bias than tests based on self-reports, useful to assess patients with schizophrenia. Generally, selfreports can have a lower discriminant power when used in patients and general population; therefore, tests presented through a paradigm are more effective for reliably replicating a real scenario; this has been demonstrated in studies showing that self-reported tests can be strongly influenced by social standards and gender expectations. In this regard, we agree that our study failed to show differences in empathy levels, since higher levels of empathy are generally obtained in females when self-report tests are used ${ }^{16}$. The factor analysis suggests that items 42 and 46 could be removed from the test. The review of these two items leads to conclude that 46 is a physical causality control item that may not be clear and, thus, proposing another paradigm can be suggested. Item 42 is an example of inhibitory empathy between two friends, where one is intoxicated with alcohol and the subject has to decide whether to let him drive or not; this example can drive us to the possibility of being faced 
with a dilemma where, due to the age of the sample, mostly young people, lower levels of care are shown for this kind of issues ${ }^{17}$. Therefore, it would be desirable for this analysis to be replicated in a sample with more heterogeneous ages.

Our study has some limitations, such as the small sample size and its selection, which was not random, and that could be a confounding factor whereby the full spectrum of severity was not obtained, which could bias the results in the comparison with the general population. For future studies, it would be advisable to create instruments to assess empathy based on mixed simulations or tests that can address the cognitive component or social tools through visual stimuli and scenarios, in order to carry out a more appropriate approach, in addition to assessing interventional maneuvers that can improve this ability, such as those based on metacognition ${ }^{18}$.

We can conclude that the instrument showed adequate psychometric properties to be used in Mexican samples; however, the sample should be expanded to improve its validity.

\section{Acknowledgements}

We are grateful to the works by Dr. Rodrigo Figueroa Vera, for their valuable help in the application of instruments.

We thank Dr. María del Carmen Lara Muñoz for her advice and guidance in this process.

\section{Funding}

The authors declare that they had no source of funding.

\section{Conflict of interests}

The authors declare that there are no conflicts of interest.

\section{Data confidentiality}

The authors declare that no patient data appear in this article.

This paper is the result of the medical sciences PhD program.

\section{References}

1. Greenberg DM, Warrier V, Allison C, Baron-Cohen S. Testing the Empathizing-Systemizing theory of sex differences and the Extreme Male Brain theory of autism in half a million people. Proc Natl Acad Sci U S A. 2018;115:12152-7.

2. Coll MP, Viding E, Rutgen M, Silani G, Lamm C, Catmur C, et al. Are we really measuring empathy? Proposal for a new measurement framework. Neurosci Biobehav Rev. 2017;83:132-9.

3. Koelkebeck K, Kuegler L, Kohl W, Engell A, Lencer R. Social cognition in schizophrenia: The role of mentalizing in moral dilemma decision-making. Compr Psychiatry. 2018;87:171-8.

4. Kállai J, Rózsa S, Hupuczi E, Hargitai R, Birkás B, Hartung I, et al. Cognitive fusion and affective isolation: Blurred self-concept and empathy deficits in schizotypy. Psychiatry Res. 2019:271:178-86.

5. Atoui M, El Jamil F, El Khoury J, Doumit M, Syriani N, Khani M, et al. The relationship between clinical insight and cognitive and affective empathy in schizophrenia. Schizophr Res Cogn. 2018;12:56-65.

6. Grant N, Lawrence M, Preti A, Wykes T, Cella M. Social cognition interventions for people with schizophrenia: a systematic review focussing on methodological quality and intervention modality. Clin Psychol Rev. 2017:56:55-64.

7. Halverson T, Jarskog LF, Pedersen C, Penn D. Effects of oxytocin on empathy, introspective accuracy, and social symptoms in schizophrenia: A 12-week twice-daily randomized controlled trial. Schizophr Res. 2019;204:178-82.

8. Baron-Cohen S, Wheelwright S. The empathy quotient: an investigation of adults with Asperger syndrome or high functioning autism, and normal sex differences. J Autism Dev Disord. 2004;34:163-75.

9. Allison C, Baron-Cohen S, Wheelwright SJ, Stone MH, Muncer SJ. Psychometric analysis of the Empathy Quotient (EQ). Pers Individ Dif. 2011;51:829-35.

10. Muncer SJ, Ling J. Psychometric analysis of the Empathy Quotient (EQ) scale. Pers Individ Dif. 2006;40:1111-9.

11. Warrier V, Toro R, Chakrabarti B, Borglum AD, Grove J, Hinds DA, et al. Genome-wide analyses of self-reported empathy: correlations with autism, schizophrenia, and anorexia nervosa. Translational psychiatry. 2018;8:35.

12. Vollm BA, Taylor AN, Richardson P, Corcoran R, Stirling J, McKie S, et al. Neuronal correlates of theory of mind and empathy: a functional magnetic resonance imaging study in a nonverbal task. Neuroimage. 2006;29:90-8.

13. Lee SJ, Kang DH, Kim CW, Gu BM, Park JY, Choi CH, et al. Multi-level comparison of empathy in schizophrenia: an fMRI study of a cartoon task. Psychiatry Res. 2010;181:121-9.

14. Batchelder $L$, Brosnan $M$, Ashwin $C$. The development and validation of the Empathy Components Questionnaire (ECQ). PLoS One. 2017;12:e0169185.

15. Heyes C. Empathy is not in our genes. Neurosci Biobehav Rev. 2018 ; 95:499-507.

16. Baez S, Flichtentrei D, Prats M, Mastandueno R, Garcia AM, Cetkovich M, et al. Men, women. who cares? A population-based study on sex differences and gender roles in empathy and moral cognition. PLoS One. 2017;12:e0179336.

17. Worly B, Verbeck N, Walker C, Clinchot DM. Burnout, perceived stress, and empathic concern: differences in female and male Millennial medical students. Psychol Health Med. 2019;24:429-38.

18. Bonfils KA, Lysaker PH, Minor KS, Salyers MP. Metacognition, personal distress, and performance-based empathy in schizophrenia. Schizophr Bull. 2019;45:19-26. 